\title{
AS CONCEPÇÕES DOS ESTUDANTES DO ENSINO FUNDAMENTAL SOBRE O CONCEITO DE POLUIÇÃO: SEGUNDO A TEORIA DE REPRESENTAÇÃO SOCIAL
}

\section{REPRESENTACIÓN SOCIAL DE ESTUDIANTES DE CONTAMINACIÓN AMBIENTAL}

\section{SOCIAL REPRESENTATION OF ENVIRONMENTAL POLLUTION STUDENTS}

Henllayane Nathani de Amorim Amaral ${ }^{1}$; Ediangela Soares Silva do Nascimento ${ }^{2}$; Ricardo Ferreira das Neves ${ }^{3}$

DOI: $\underline{\text { https://doi.org/10.31692/978-65-991061-3-2.124-128 }}$

\section{INTRODUÇÃO}

A escola representa um espaço educacional que busca estimular o pensamento crítico e o desenvolvimento dos estudantes oportunizando-os, consolidando os princípios de uma formação para a cidadania e a consciência diante de situações emergenciais, como os impactos da poluição no ambiente (SEGURA, 2001). Assim temas como a poluição podem ser impetrados nas aulas de ciências como problematizadores, de forma a contribuir para a sua reflexão sobre as ações antrópicas ao ambiente. Diante disso, é notório que os estudantes estão imersos em informações culturais que fomentam a sua vida cotidiana e que por vezes, influenciam nas suas interpretações sobre determinados assuntos.

Hoje, por causa do crescente aumento da poluição ambiental em todos os níveis; compreendendo o entendimento do sujeito diante de conteúdos dessa natureza e a partir disso, incentivar desde cedo às práticas de Educação Ambiental.

Nessa direção, Sander (1992) orienta que o processo de transformação da sociedade atual em sociedade sustentável correrá mediante, a prática da cidadania através das informações e conceitos no âmbito educativo, ou seja, a escola precisa instigar os estudantes a refletirem sobre seus posicionamentos a cerca ambiente, inserindo discussões, por exemplo, sobre a poluição. Nesse sentido, a Teoria das Representações Sociais de Serge Moscovici é uma opção para o detalhamento e explicação de acontecimentos sociais, tendo em vista que representam pensamentos e comportamentos comuns aa um grupo de indivíduos (MOSCOVICI, 1978).

Nessa perspectiva, aspiramos saber sobre como estudantes da Educação Básica

\footnotetext{
1 Graduanda em Ciências Biológicas na Universidade Federal de Pernambuco, UFPE/CAV, henllayane16@gmail.com

2 Graduanda em Ciências Biológicas na Universidade Federal de Pernambuco, UFPE/CAV, ediangelacbio@gmail.com

${ }^{3}$ Professor da Universidade Federal de Pernambuco, UFPE/CAV, rico.neves2010@ gmail.com
} 
compreendem. Assim, temos como objetivo: analisar a representação social de alunos do Ensino Fundamental sobre poluição ambiental.

\section{A poluição ambiental: algumas considerações}

Segundo as organizações das Nações Unidas (ONU), poluição ou contaminação ambiental é uma alteração do Meio Ambiente que pode afetar a saúde e integridade dos seres vivos. Representa alterações físicas, químicas ou biológicas resultante das atividades humanas e que podem afetar o equilíbrio do ecossistema e ainda ser causada por fatores naturais antrópicos, gerando impactos que interferem significativamente no ambiente (ARRUDA et al, 2001).

A Lei 9.394/96, em seu Artigo 32, enfatiza que o Ensino Fundamental tem por objetivo a formação básica do cidadão mediante a compreensão do ambiental, natural e social do sistema político, da tecnologia das artes e dos valores da sociedade. No Artigo 36, aponta que os currículos da Educação Básica, possui uma base diversificada que deve fomentar as características regionais e locais da população, envolvendo o conhecimento do mundo físico e natural, e da realidade social e política brasileira (BRASIL, 1996).

Diante disso, os Parâmetros Curriculares Nacionais (PCN) indicam a necessidade de investigação das alterações ambientais, decorrentes da emissão de substâncias, partículas e outros materiais poluidores, buscando alternativas para o controle da poluição (BRASIL, 2000).

Assim, a introdução de temas ambientais nas aulas possibilita a aprendizagem de conceitos básicos e abre um leque de informações complementares, cuja escola pode instigar a reflexão sobre valores e atitudes para a formação de uma consciência ambiental.

\section{A Teoria da Representação Social}

A Teoria da Representação Social (TRS) envolve a produção dos saberes social, aqueles que são produzidos no cotidiano, e que pertencem ao mundo vivido (JOVCHELOVITH, 1998).

Moscovici (1978) considera as representações como algo compartilhado de modo heterogêneo pelos diferentes grupos sociais. Foi na obra "La Psychanalyse, son image et son public", de 1961, que o autor mencionou pela primeira vez o conceito de Representação Social, desenvolvendo a partir deste uma psicossociologia do conhecimento. Dessa forma, o conhecimento é adquirido por meio da compreensão alcançada por indivíduos que pensam, porém, não sozinhos, pois a semelhança dos pronunciamentos feitos por um grupo demonstra o que pensaram juntos sobre os assuntos. 
Para Moscovici (1978), as Representações Sociais são entidades quase tangíveis. Elas circulam, cruzam-se e cristaliza-se incessantemente, por intermédio de uma fala, um gesto, um encontro em nosso universo cotidiano, constituindo, assim, uma modalidade de conhecimento particular que tem por função a elaboração de comportamentos e a comunicação entre os indivíduos.

Assim, tem-se na representação um reflexo da realidade, atuando nas relações dos indivíduos no âmbito físico e social, determinando suas práticas e orientando ações, interações sociais, antecipações e expectativas.

\section{METODOLOGIA}

Por meio de uma pesquisa qualitativa, o estudo foi realizado com uma turma do Ensino Fundamental - Anos Finais, composta por 25 estudantes numa escola pública, em Vitória de Santo Antão.

Para a coleta dos dados foi utilizado um questionário subjetivo baseado na proposta metodológica de Abric (1998), cujo instrumento contemplou dois momentos. Inicialmente, foi solicitado que os alunos escrevessem em uma folha, cinco palavras que elas relacionassem com a poluição ambiental, em ordem de significância. Posteriormente, quando da primeira palavra, com maior grau de importância, os estudantes deveriam descrevê-la.

Para a análise, foi verificado o valor de frequência das palavras que mais apareceram nas respostas dos estudantes, e posteriormente, calculamos as que mais se repetem. Temos então, a representação social dos alunos em relação à poluição ambiental.

\section{RESULTADOS E DISCUSSÕES}

Os resultados encontrados no presente estudo apontam como a palavra mais representativa sobre a poluição recebeu mais destaque entre as demais foi "LIXO" com 14 aparições entre 25 resultados, conforme o quadro 1 e suas considerações a partir do quadro 2 , a seguir:

Quadro 1. Frequência das palavras destaque sobre o conceito de poluição

\begin{tabular}{|l|l|l|}
\hline \multicolumn{1}{|c|}{ Palavra } & \multicolumn{1}{|c|}{ Quantidade } & \multicolumn{1}{c|}{ Frequência } \\
\hline Lixo & 14 & $56 \%$ \\
\hline Desmatamento & 6 & $24 \%$ \\
\hline Queimadas & 3 & $12 \%$ \\
\hline Petróleo & 2 & $8 \%$ \\
\hline
\end{tabular}

Fonte: Própria (2019). 
Quadro 2. Descrições dos estudantes sobre o conceito de Poluição

\begin{tabular}{|c|c|}
\hline Estudantes & Descrições \\
\hline 1. & "O lixo é o mais poluente que tem é o mais que tem pelas ruas" \\
\hline 2. & $\begin{array}{l}\text { "O lixo jogado na rua é uma poluição do ar e do solo, pois não } \\
\text { jogue lixo na rua para não poluir o solo." }\end{array}$ \\
\hline 3. & "O lixo é uma poluição meio grave causando muitas mortes." \\
\hline 4. & $\begin{array}{l}\text { "O lixo é uma das principais poluições pelo brasil que acaba } \\
\text { matando animais marinhos como a tartaruga que pode comer um } \\
\text { saco plástico." }\end{array}$ \\
\hline 5. & $\begin{array}{l}\text { "O lixo é um tipo de poluição o que pode poluir qualquer ambiente } \\
\text { seja ele terrestre ou marinho." }\end{array}$ \\
\hline 6. & "É o resto de algo que não presta e vira lixo." \\
\hline 7. & $\begin{array}{l}\text { "Se você ve uma lixeira perto de você, você vai jogar no lixo ou no } \\
\text { chão eu jogava na lixeira." }\end{array}$ \\
\hline 8. & $\begin{array}{l}\text { "Lixo é muita poluição pra terra agente mesmo que causa esta } \\
\text { poluição por que joga o lixo na atmosfera." }\end{array}$ \\
\hline 9. & $\begin{array}{l}\text { "As pessoas fica jogando lixos nos rios e pega os peixes morrem } \\
\text { por causa dos humanos." }\end{array}$ \\
\hline 10. & "É a poluição que suja os rios." \\
\hline 11. & "É uma coisa que prejudica o meio ambiente." \\
\hline 12. & $\begin{array}{l}\text { "É uma coisa poluída na atmosfera que prejudica o nosso país } \\
\text { causa doenças para o mundo doenças muito ruins." }\end{array}$ \\
\hline 13. & "É a poluição do meio ambiente, que joga o lixo no meio da rua." \\
\hline 14. & "É causado pela população." \\
\hline
\end{tabular}

Ao decorrer do processo de levantamento de dados podemos notar diferenças entre a representação dos alunos previamente sobre poluição. Apesar da palavra "LIXO” persistir em destaque, é perceptível que os estudantes obtiveram maior abrangência das variedades e causas da poluição e não se restringiram apenas aqueles tipos mais comuns, que na maioria das vezes recebe maior visibilidade por causa da mídia.

\section{CONCLUSÕES}

A partir da Teoria da Representação Social foi possível percebermos a significância da relação entre poluição e lixo, oriunda de informações midiáticas e de ações sociais, como percursora desse tipo de problemática. É válido ressaltar, a importância de se trabalhar a poluição logo na infância, pois o indivíduo pode repensar suas práticas ao Meio Ambiente, estimulando a adoção de uma postura mais crítica.

\section{REFERÊNCIAS}

ABRIC, J. A abordagem estrutural das representações sociais. In: Moreira, A. S. P. estudos 
interdisciplinares de representação social. Goiânia: AB, 1998.

BRASIL. Lei de Diretrizes e Bases da Educação Nacional n. 9.394. Brasília: MEC, 1996.

BRASIL. Parâmetros curriculares nacionais: Ciências Naturais. Secretaria de Educação Fundamental. Brasília: MEC/SEF, 1998.

BRASIL, Secretaria de Educação Fundamental. Parâmetros Curriculares Nacionais: Ciências da Natureza, Matemática e suas Tecnologias. Brasília: MEC/SEF, 2000.

JOVCHELOVITCH, S. Re(des)cobrindo o Outro: Para um entendimento da alteridade na teoria das representações sociais. In A. ARRUDA (Ed) Representando a Alteridade. Petrópolis, RJ: Vozes, 1998.

MOSCOVICI, Serge. A representação social da psicanálise. 1.ed. Rio de Janeiro: Zahar, 1978. Representações Sociais: investigação em psicologia social. Petrópolis, RJ: Vozes, 2003.

SANDER, B. Administração da educação no Brasil: é hora da relevância. São Paulo: Cortez, 1992.

SEGURA, Denise de S. Baena. Educação Ambiental na escola pública: da curiosidade ingênua à consciência crítica. São Paulo: Annablume: Fapesp, 2001. 